\title{
EMPLOYEES MOTIVATION AND MANAGERIAL COACHING DURING THE COVID-19 PANDEMIC
}

\author{
Tanja Stanković ${ }^{1 *}$, \\ Tijana Radojević \\ ${ }^{1} \mathrm{PhD}$ candidate, \\ Singidunum University, \\ Belgrade, Serbia \\ MMI Bor, \\ Bor, Serbia \\ ${ }^{2}$ Singidunum University, \\ Belgrade, Serbia
}

\begin{abstract}
:
Company survival depends on its ability to adapt to the changes that have their own pace and dynamics of development. It is the transition from the present to the future, a state which is often desired. Without motivation, the organization's management activities will lose its relevance and cannot be successfully implemented. Employee motivation factors for work, advancement and organizational change are numerous, but the most important is the communication between employees and management. As this communication is closely related to management coaching, manager's coaching skills become crucial for motivation and ultimate success of the organization. This research aims to show the importance of motivating employees to learn and improve skills at work, and identify the best individuals who can become internal trainers who will transfer their knowledge to employees.
\end{abstract}

Keywords:

employee motivation, employee and management communication, managerial coaching, coaching skills.

\section{INTRODUCTION}

As the management deals with the integration of employees in a joint venture process, we can consider it as a part of our culture. There are many definitions of management, starting from management, leadership, up to organization. Etymologically, the word management comes from the Italian word manege-iare, which is derived from the Latin word hand (manus), hence the word leadership. The word management derives from the base of English words man and age, which associates us with the management of an experienced man. Management is described differently in many textbooks, as a process, function, coordination, skill, shaping. The success of any organization depends on numerous factors. This is where we come to the relationship between management and employees. Good management has a positive effect on employee motivation, which depends on communication between them. Good mutual communication is one of the ways to create a motivating work environment. In order to achieve better communication between management and employees, managers must have special coaching skills and based on them to conduct a specific managerial coaching process. After a brief review of employee motivation in general and its dependence on communication within the organization, this paper specifically addresses the topics of managerial coaching and coaching skills of managers and their impact on employee motivation. The processing was performed on the basis of reviewed cited literature as well as based on practical research on this topic.
Correspondence:

Tanja Stanković 


\section{EMPLOYEE MOTIVATION AND COMMUNICATION}

Motivation in general, represents strength within one personality that conditions certain instrumental actions to achieve set goals. It is directly dependent on communication between management and employees. Most of the authors see motivation as a process of meeting personal needs including these steps:

- Unmet needs

- Activity

- Searching for solutions

- Meeting needs

- Easing of tension

It is easy to conclude, on the basis of cited steps, that employees are doing their best to ease the tension and continue with the progress (Cvetković, 2014). The motivation of management and individual leaders is important as well as the motivation of all members of the organization. Motivation is needed to perform any job, in addition to knowledge, abilities or skills. Regardless of what theories may propound, motivated people will invest more effort in their work than those unmotivated (Radojević, Stanković, Rajin, 2020). Motivation is a generally accepted term for all factors that affect the organization and management of people and their habits. It is desirable to create conditions in which the qualities of employees will become recognizable, to look for chances to extract potential from people. Motivation is the willingness of a person to meet the goal while fulfilling personal needs (Ferjan, 1998). Today, most of the theories of motivation have been developed in the USA. However, all theories do not apply to all cultures. In some cultures, the priority is a secure job and lifelong employment, ahead of challenges, career and social needs. Therefore, the factors that motivate employees in USA will not motivate employees in other countries likewise (Adler and Gunderson, 2007).

There is no unique solution how to motivate employees. We will cite a famous quote from a founder of china's social media, Jack Ma: "Opportunities lie in the place where the complaints are", implying that solutions and opportunities should not be sought, because they exist, the market should only be listened to. Even in a hopeless situation, new opportunities for success can be created, and the outcome is a motivated employee who is ready to seize these circumstances. Employee motivation is influenced by many internal factors (the character of an individual, work habits) and external factors (living standard, moral and values system, socio-economic development) (Rahimić, Resić, Kožo, 2012). Productive communication as an essential task of managers implies informing employees about the success of colleagues, the course and progress of changes in the company and reducing feelings of uncertainty and insecurity. Communication as the exchange of information must be planned and well organized by top management, teams, and services. To motivate employees during any communication, managers should use channels or different media of communication like internal newspapers, emails, bulletin boards, meetings, face-to-face conversations, or persuasion techniques, and not employees' emotions (Janićijević, 2014). While motivating employees, we must not forget that internal communication is a vital factor. If this requirement is not met, there are no good relations between employees and management. In that case, we say that there is no two-way communication. Then the human potential leaves the organization, so it remains without support for the planned organizational changes. We will agree that, without good communication, it is difficult to influence the motivation of employees. That is why a good balance of these two factors is an imperative.

As the relationship of communication between employees and management is closely related to management coaching, for management coaching to be successful, a manager must have good coaching skills that are important to motivate employees and succeed together with them.

\section{MANAGERIAL COACHING AND MANAGER COACHING SKILLS}

\subsection{MANAGERIAL COACHING}

Most definitions of managerial coaching emphasize the role of leaders in facilitating the development of their employees. Coaching is a long-lasting process and certainly is not a process of fixing or repairing something. Understanding the needs or business perspectives is all about the coaching. When applying coaching techniques, the motivation of workers develops, fluctuation decreases because the trained workers become attached to their job. The goal of coaching is to get a motivated employee ready to meet personal and organizational needs. Coaching brings out the best in people and directs them to future business trends. Investing in coaching is an expensive, but profitable discipline. There is another side of coaching that prepares an employee for multiple career changes, because a diploma and a steady job are sometimes not enough for a lifetime, so they are looking for a better job. The most engaged are those who have an extensive education and skills that could be used in different situations.

From all the above-mentioned, we can conclude that managerial coaching presents the encouragement and release of human potential which is used to increase the performance of an individual or team. 
Managerial coaching has a direct impact on improving the life and role of employees, work performance, job satisfaction, and commitment to career.

\subsection{MANAGERS COACHING SKILLS}

Job satisfaction is an important indicator of work motivation, but employees are a vital factor in the success of a modern organization, that is why it is crucial to manage and coach them carefully. For an organization to successfully manage staff, it needs a good leader who possesses coaching skills that the employees will adopt. The diverse and portable skills of managers are the basis of good management. Four skills that appear to present a particular challenge to the managerial coach are the following (Lawrence, 2017):

- Good relationship among employees

- Communication skills

- Mentoring skills

- Negotiation skills

For managers to be good internal or external coaches, they need to have empathy, willingness, and motivation for helping others to solve problems and improve current circumstances. Using coaching skills, a coach teaches employees and managers how to gain necessary knowledge. Both, external or internal coach, support leaders and managers to manage and operate their business and employee challenges.

An external coach is hired by the organization to meet its expectations within the predicted time frame. They accredit training methods and expertise in skills that meet the needs of the client. Hiring them is expensive, but error correction is even more expensive and the investment in coaching will generate the return. Besides rigidity, the main disadvantage of external coach is unfamiliarity with the culture or ethics within the organization.

On the other hand, there is an internal coach. They are trained within the organization, they are cost-effective and popular, familiar with the employees, organizational needs, and know each other on a personal level.

No matter how great the necessity for a coach is, managers can still be suspicious and unprepared if they are not trained (Ladyshewsky 2010). However, if managers have had a positive experience of being coached, they are more likely to want their coworkers to undergo coaching and to expand their coaching skills. Coaching skill training is an appropriate first step, but it is not enough. Organizations need to create a coaching supportive culture to ensure the continuous application and modeling coaching skills patterns (McCarthy and Milner, 2013). We can summarize that the skills of a successful coach are:
- Distinctive ability to communicate

- Precise judgment

- Ability to take appropriate actions

- Not invading the privacy of others

- Incentive spread of tacit knowledge

In addition to the above-mentioned skills, it is necessary for the coach to be trusted, to take responsibility for his actions, to maintain dignity and calmness, to possess good manners. When using communication and motivation skills, a manager can positively or negatively influence employees. It largely depends on the level of his motivation. The positive influence of the coach in this context can trigger positive organizational changes and successful management of these changes, but also vice versa.

\section{MANAGERIAL COACHING IN MINING AND METALLURGY INSTITUTE BOR (MMI)}

Practical research conducted in MMI within this paper was performed by applying methods of data collection through survey and observations, as well as analysis of the content of relevant sites, legal regulations and reports. Among 250 employees, MMI has 48 doctoral students and $25 \mathrm{PhD}$ 's, it is well equipped with services that have managed to secure a place among the best institutes in the region (https://irmbor.co.rs/en/about-us/employees/). As an institute that invests a lot in development, training, education of their staff, doctoral studies etc., it can be considered a learning organization. A large number of doctoral students and Doctors of Science, a large number of experienced engineers, ranks this institute among the best ones. It can be learned from MMI how to move through different economic situations that are conditioned by various factors, including the impact of the pandemic. Within its activity MMI performs the development of the scientific-research projects in the fields of geology, mining, metallurgy, technology, expertises, studies and projects of interdisciplinary character providing the technological infrastructure development of the interest of the Republic of Serbia (Stanković, 2020).

The growth of economic activities in Bor district, primarily in Bor and Majdanpek, is conditioned by the arrival of a strategic partner and a huge investment in capacity building in mining. It caused the engagement of all employees in a large company that bought the former RTB Bor, but it also conditioned that its partners and suppliers of materials and services work with increased capacity. In order to put into operation as quickly and efficiently as possible every plant in Bor and Majdanpek, the Chinese partner invested huge funds, which required MMI engagement to a far greater extent compared to the situation before the arrival of a strategic partner. 
The specific conditions reflected on increased intellectual services that brought good earnings, liquidity, performance, and GDP to MMI. Here it comes to the impact of the COVID-19 pandemic in MMI. With all the security measures recommended during the impact of the pandemic, wearing masks, keeping distance, reduced travels, online meetings etc. came up with the idea of organizing internal training named „Teach the teacher” so that external experts could transfer their knowledge to mid-level management who will pass that knowledge to the groups of employees. The goal of the coaching was to spread knowledge of English, computer skills, ethics during communication with other cultures, designing and field sampling. The employees were responsible to themselves and their colleagues, with the motto "safety first”. Training has become a standard method of work during which the active participation of all employees was taken through panel discussions, group work, case study analysis. An electronic attendance record was kept at all times, which was later used for motivation through rewards such as paid leave, better pay, employment of an educated family member, paid schooling. All these procedures of MMI management have been designed to increase productivity during pandemics and better understanding with a strategic partner.

\section{SURVEY ON EMPLOYEES' ATTITUDES TOWARDS MOTIVATION AND COACHING IN MMI BOR}

Practical research of the employee's attitudes on the motivation for engaging in MMI in relation to coaching was based on the case study analysis of the conducted trainings in 2020-21 during the ongoing global COVID-19 pandemic. Due to the impossibility of sending employees for training and development, MMI found a way to organize internal training and encourage employees by internal managers, who are experts in specific areas, to develop motivation, habits, and knowledge. The questionnaire compiled was based on searched electronic data sources and examples used in similar previous research. The survey was conducted on a sample of 50 respondents, employed in MMI using a questionnaire that contained 5 general and 10 specific questions grouped into two parts:

- Attitudes of employees about coaching practice in MMI and

- Attitudes of employees about coaching skills of managers in MMI

Each of the questions asked required a simple answer with one of the 5 options offered:

1 - completely incorrect

2 - mostly incorrect

3 - I'm not sure

4 - mostly correct

5 - quite true

The answers were classified into one of the following three groups of answers that indicate the degree of motivation of MMI employees in the context of coaching and coaching skills of management:

- motivated (answers with options 4 and 5),

- Insufficiently motivated (answers with option 3)

- unmotivated (answers with options 2 and 1).

The questionnaire, forwarded to the respondents, was designed in the following manner:

QUESTIONNAIRE

EMPLOYEE MOTIVATION AND COACHING IN MMI BOR

The questionnaire in front of you is used to collect data on motivation of MMI employees, which will be used exclusively for the purpose of preparing a scientific paper:

The level of employees' motivation in the context of managerial coaching during the COVID-19 pandemic

The questionnaire has two parts:

I Respondent data

II Attitudes about motivation and management coaching

The questionnaire is anonymous.

I am grateful for your cooperation! 


\section{RESPONDENT DATA}

Please answer the following questions by circling one option:

\begin{tabular}{lccccc}
\hline Gender (M / F): & \multicolumn{1}{c}{} & & & \\
\hline Age: & -30 & $30-40$ & $40-50$ & $50-60$ & $60+$ \\
\hline Years of service: & -5 & $5-10$ & $10-20$ & $20-30$ & $30+$ \\
\hline $\begin{array}{l}\text { Professional } \\
\text { qualifications: }\end{array}$ & Medium & Higher & High & MSc & PhD \\
\hline Title: & Untitled & Professional & Professional & Scientific \\
\hline
\end{tabular}

\section{ATTITUDES ABOUT MOTIVATION AND MANAGEMENT COACHING}

Please enter a number next to each question that indicates your degree of agreement, with the following statements: 1 - completely incorrect, 2 - mostly incorrect, 3 - not sure, 4 - mostly correct, 5 - quite true

\section{QUESTIONS /ATTITUDES}

\section{ATTITUDES ABOUT MANAGEMENT COACHING}

1. I am satisfied with the organization of internal training in 2020

2. Internal training organized in 2020 was purposeful for my working activities

3. There has been enough internal training in previous years

4. The training I attended had its use in practice

5. It would be useful to have various new trainings in the future

II ATTITUDES ABOUT MANAGERS COACHING SKILLS

1. I am satisfied with the knowledge and presentation of external trainers

2. I am satisfied with the quality of knowledge transfer by internal trainers

3. The knowledge of internal trainers is at a high level regarding the quality and usefulness of the trainings

4. The skills of internal trainers are at a high level regarding the quality and usefulness of the trainings

5. I think that in the future I could pass on the acquired knowledge to younger colleagues

The questionnaires were properly filled out by all 50 employees from the observed sample. All respondents answered all the questions asked. After receiving the answers, a sample of respondents who filled in the questionnaire was reviewed and then all their answers were analyzed in detail. The part of the performed analysis that served for the final conclusions based on this research is shown in the following table. 


\begin{tabular}{|c|c|c|c|c|c|c|}
\hline \multirow{3}{*}{ Questions } & Aswers & Answer & Answers & Answers & Answer & Answers \\
\hline & 1 and 2 & 3 & 4 and 5 & 4 and 5 & 3 & 1 and 2 \\
\hline & $\begin{array}{c}\text { Number of } \\
\text { responses }\end{array}$ & $\begin{array}{c}\text { Number of } \\
\text { responses }\end{array}$ & $\begin{array}{c}\text { Number of } \\
\text { responses }\end{array}$ & $\%$ & $\%$ & $\%$ \\
\hline I & 142 & 90 & 18 & 57 & 36 & 7 \\
\hline 1. & 30 & 16 & 4 & 60 & 32 & 8 \\
\hline 2. & 35 & 10 & 5 & 70 & 20 & 10 \\
\hline 3. & 19 & 30 & 1 & 38 & 60 & 2 \\
\hline 4. & 18 & 30 & 2 & 36 & 60 & 4 \\
\hline 5. & 40 & 4 & 6 & 80 & 8 & 12 \\
\hline II & 124 & 92 & 34 & 50 & 37 & 13 \\
\hline 1. & 39 & 6 & 5 & 78 & 12 & 10 \\
\hline 2. & 30 & 17 & 3 & 60 & 34 & 6 \\
\hline 3. & 30 & 18 & 2 & 60 & 36 & 4 \\
\hline 4. & 5 & 30 & 15 & 10 & 60 & 30 \\
\hline 5. & 20 & 21 & 9 & 40 & 42 & 18 \\
\hline In total & 266 & 182 & 52 & 53 & 37 & 10 \\
\hline
\end{tabular}

\subsection{CONCLUSIONS AND PROPOSALS FOR IMPROVING THE PRACTICE OF MOTIVATION AND COACHING IN $\mathrm{MMI}$}

By analyzing the sample of MMI employees who filled in the questionnaire within the conducted survey, it was determined and concluded that it is sufficiently representative.

The number of respondents is approximately $28 \%$, and that is relatively considerable coverage that contributes to representativeness. According to age, the sample consists of employees between 30 and 55 years of age. The sample included employees with 5 to 25 years of work experience. According to title and education, the case study is dominated by employees with master and doctor of science degrees. After a detailed analysis of the answers from the questionnaire, the following conclusions were adopted:

1) The answers to the questions from group I indicate that the MMI employees perceive coaching management differently in the context of its impact on work motivation and greater engagement:

- $57 \%$ of employees are motivated for work and greater engagement with the support of management coaching (the answers with options 4 and 5).

- $36 \%$ of employees gave the answer with option 3 (I'm not sure) and they can be classified as relatively motivated for work and greater engagement with the support of management coaching.
- $7 \%$ of employees could be classified as unmotivated for work and greater engagement with the support of management coaching.

2) Based on the answers from the group II (Attitudes about managers coaching skills), it can be concluded that employees perceive managers coaching skills differently in terms of the impact on their greater motivation:

- $50 \%$ of employees gave the answers with options 4 and 5 (mostly correct and quite true) and they can be classified as motivated for work and greater engagement based on the perception of managers coaching skills.

- $37 \%$ of employees can be classified into a group of relatively motivated for work and greater engagement based on the perception of managers' coaching skills.

- $13 \%$ of employees are classified as unmotivated for work and greater engagement based on the perception of managers' coaching skills, answers with options 1 and 2 (incorrect and mostly incorrect).

According to the entire questionnaire, it can be concluded that the MMI employees are relatively well motivated to engage with the support of management coaching. 53\% of them are motivated based on the answers (options 4 and 5). 37\% of employees are relatively motivated based on the total number of responses with option 3. In line with the total number of negative responses (options 1 and 2) only $10 \%$ of employees can be considered unmotivated. Since unmotivated people are not committed to the success of the company, it could be suggested 
that personality traits should be explored as they show a future impact on coach implementation. With all the limitations and shortcomings of the research, based on its findings, it is justified to propose several measures that would improve employees' motivation with the support of management and managers coaching skills in the future work of MMI:

- Increase the number of internal trainings by areas of activity in different fields of work

- Increase the number of managers who will coach

- Improve the coaching skills of internal coaches

- Determine what motivates the employee on a daily basis

- Praise good results and employee advancement

- Align business with the pandemic movement

MMI has confidence in its people, believes in costeffectiveness in development and additional employees' education to easily adapt to any change. It should be stated that it is necessary to continuously improve the communication between management and employees, which, among other things, implies good managerial coaching and developed coaching skills of managers. It is also very important to build an atmosphere of trust with a strategic partner who has certainly contributed to improving the employee lifestyle.

\section{CONCLUSION}

This paper is based on reviewed and cited literature on the theory of the relationship between employee motivation and managerial coaching conducted by its management, as well as on the basis of original research conducted on this topic. The pandemic continues to affect all aspects of our personal lives, our families, our professions, jobs, research, it has forced the world community to start using the information technology as well as other learning opportunities as to acquire new knowledge and learning materials to keep up with the rest of the world. The following recommendations are given for future theorists and practitioners in this field:

- Research should focus on employee motivation in the process of upskilling or reskilling at work;

- Certain aspects of motivation for learning and training in the workplace should be further studied and aligned with possible emergencies;

- External or internal trainers must always be continuously trained and up to date with new knowledge in the field of their expertise.

\section{LITERATURE}

Adler, N., Gunderson, A. (2007), International Dimensions of Organizational Behavior, 5th ed. Cengage Learning

Cvetković, M. (2014), Nematerijalna i unutrašnja motivacija zaposlenih u savremenim organizacijama, Master rad, Singidunum Beograd

Ferjan, M. (1998), Poslovno komuniciranje, Moderna organizacija, Kranj

Janićijević, N. (2014), Ljudi u promenama, promene u ljudima, Ekonomski fakultet, Beograd

Ladyshewsky, R.K. (2010), The manager as coach as a driver of organizational development, Leadership \& Organization Development Journal, 31 (4), pp. 292-306

Lawrence, P. (2017), Managerial coaching-A literature review, International Journal of Evidence Based Coaching and Mentoring, 15(2), pp. 43-65

McCarthy, G., Milner, J. (2013), Managerial coaching: challenges, opportunities and training. Journal of Management Development, 32 (7), 768-779

Radojević, T., Stanković, T., Rajin, D. (2020), Employee motivation in the process of managing organizational change, Finiz - Singidunum University International Scientific Conference, pp. $152-160$

Rahimić, Z., Resić, E., Kožo, A. (2012), Determining the level of management competences in the process of employee motivation. Procedia-Social and Behavioral Science, 41, 535-543.

Stanković, T. (2020), Motivacija zaposlenih u procesu upravljanja organizacionim promenama, Master rad, Univerzitet Singidunum, Beograd 